\title{
PERANCANGAN SMART DOOR LOCK MENGGUNAKAN VOICE RECOGNITION BERBASIS RAPBERRY PI 3
}

\author{
Diah Aryani $^{1}$, Dedy Iskandar ${ }^{2}$, Fitri Indriyani ${ }^{2}$ \\ ${ }^{1}$ Dosen STMIK Raharja Jurusan Teknik Informatika, ${ }^{2}$ Dosen STMIK Raharja Jurusan \\ Manajemen Informatika, ${ }^{3}$ Mahasiswa STMIK Raharja Jurusan Sistem Komputer \\ 1,2,3 Jl.Jendral Sudirman No.40, Modern Cikokol, Tangerang \\ e-mail:1'diah.aryani@raharja.info, ${ }^{2}$ iskandar@raharja.info, ${ }^{3}$ fitri.indriyani@raharja.info
}

\begin{abstract}
The server door is the main access to enter the server room. Currently the door lock on the server room is still done manually using the physical key as a tool to open or lock the door. Physical keys are easily lost or left behind which results in the officer not being able to enter the server room. This resulted in the officer can not access the server. Based on these reasons, the server door is integrated with a computer system that can unlock the door using voice recognition to unlock the server door. Voice recognition is able to identify a person through his voice. Voice recognition is divided into 2 parts namely speech recognition and speeker recognition. Meanwhile, the authors use the speech recognition section to open the door server door lock. Where, speech recognition can identify what is spoken by someone. The design of this tool is made using Raspberry pi 3 as the processing center and ULN2803 as ic to increase the voltage so that it can move the solenoid that serves to move the doorlock. Then raspberry gives command to the servo motor to open the door. Only staff who have id and password are only able to open the door lock on the server room using voice recognition. While those who do not have id and password can not unlock the door in the server room. So with the design of smart door lock tool using voice recognition raspberry-based pi 3 provides a level of security and access more computerized.
\end{abstract}

Keywords: Voice Recognition, Raspberry pi 3, Doorlock

\begin{abstract}
Abstrak
Pintu server merupakan akses utama untuk memasuki ruangan server. Saat ini kunci pintu pada ruangan server masih dilakukan secara manual menggunakan kunci fisik sebagai alat untuk membuka atau mengunci pintu. Kunci fisik mudah hilang atau tertinggal yang mengakibatkan petugas tidak dapat masuk ke dalam ruangan server. Hal tersebut mengakibatkan petugas tidak dapat mengakses server. Untuk menyelesaikan permasalahan tersebut, maka dirancanglah pintu server yang terintegrasi dengan sistem komputer yang dapat membuka kunci pintu menggunakan voice recognition untuk membuka kunci pintu server. Voice recognition yaitu dapat mengidentifikasi seseorang melalui suaranya. Voice recognition ini terbagi menjadi 2 bagian yaitu speech recognition dan speeker recognition. Sementara itu penulis menggunakan bagian speech recognition untuk membuka kunci pintu server. Dimana, speech recognition dapat mengidentifikasi apa yang diucapkan oleh seseorang. Perancangan alat ini dibuat menggunakan Raspberry pi 3 sebagai pusat pemroses dan ULN2803 sebagai ic untuk meningkatkan tegangan sehingga dapat menggerakan solenoid yang berfungsi untuk menggerakkan doorlock. Kemudian raspberry memberikan perintah ke motor servo untuk membuka pintu. Hanya staff yang memiliki id dan password saja yang hanya dapat membuka kunci pintu pada ruangan server menggunakan voice recognition ini. Sedangkan yang tidak memiliki id dan password tidak dapat membuka kunci
\end{abstract}


pintu pada ruangan server. Sehingga dengan perancangan alat smart door lock menggunakan voice recognition berbasis raspberry pi 3 memberikan tingkat keamanan dan akses yang lebih komputerisasi.

Kata Kunci: Voice Recognition, Raspberry pi 3, Doorlock

\section{PENDAHULUAN}

Saat ini perkembangan teknologi dibidang elektronika dan komunikasi berjalan begitu pesat. Seiring dengan naiknya kebutuhan masyarakat maka teknologi sangat berperan sekali untuk membantu mempermudah pekerjaan manusia, maka dibuatlah suatu sistem kontrol robot yang dapat dikendalikan dengan menggunakan smarphone.

Sementara itu, untuk membuka atau mengunci pintu masih dilakukan secara manual diberbagai instansi salah satunya yang terdapat pada ruangan server di Perguruan Tinggi Raharja yang masih menggunakan kunci fisik sebagai alat untuk membuka atau mengunci pintu. Sedangkan, kunci fisik mudah hilang atau tertinggal yang mengakibatkan staf tehnik perguruan tinggi raharja tidak bisa masuk ke dalam ruangannya. Hal tersebut mengakibatkan staf tehnik tidak dapat mengakses server yang ada pada perguruan tinggi raharja.

Berdasarkan permasalahan di atas, penulis membuat suatu alat yang dapat di gunakan untuk membuka kunci pintu suatu ruangan berbasis respberry pi 3 yang mampu membaca sinyal masukan suara yang di gunakan untuk menggerakan solenoid yang berfungsi menggerakkan doorlock. Kemudian raspberry memberikan perintah ke motor servo agar pintu ruangan dapat di buka otomatis. Oleh karna itu perancangan alat ini dapat diaplikasikan untuk membuka kunci pintu pada ruangan server secara otomatis dan dapat memfasilitasi sistem keamanan yang di butuhkan.

\section{PERMASALAHAN}

Kunci pintu merupakan akses sebuah pintu. Pada umumnya kunci pintu masih menggunakan kunci konvesional sebagai alat untuk membuka atau mengunci pintu. Sementara itu dengan menggunakan kunci pintu konvesional memiliki kelemahan yaitu human eror atau pemegang kunci terkadang lupa menaruh kunci pintu yang mengakibatkan tidak dapat membuka kunci pintu.

Rumusan masalah dalam penelitian ini adalah

1. Bagaimana merancang raspberyy pi 3 agar dapat memberikan perintah untuk membuka kunci pintu?

2. Bagaimana merancang sistem pembuka kunci pintu mengunakan voice recognition berbasis raspberry pi 3 ?

3. Apakah penggunaan voice recognition lebih mudah digunakan dibanding menggunakan kunci konvesional untuk membuka atau mengunci pintu.

Berdasarkan rumusan masalah yang telah diidentifikasi, maka manfaat dan tujuan yang ingin dihasilkan adalah meningkatkan inovasi dan kreatifitas dalam menciptakan sebuah karya yang mengimplementasikan ilmu teknologi informasi dan komunikasi,dapat meminimalisir kehilangan kunci yang mengakibatkan tidak dapat membuka pintu ruangan,dapat mengurangi pencurian, serta memberi kemudahan kepada staff untuk masuk dalam ruangan tanpa menggunakan kunci konvesional.

\section{LITERATURE REVIEW}

Literature review ini dilakukan oleh penelitian dalam upaya melengkapi dan kedepannya. Adapun Literature Review sebagai landasan dalam mendukung penelitian adalah sebagai berikut: 
1. Penelitian yang dilakukan oleh Muhammad Akbar Fadillah 2016 yang berjudul "Sistem Keamanan Ruangan Menggunakan Voice Via Bluetooth Berbasis Arduino Pada Kementerian Agama Kabupaten Tangerang". Penelitian ini membahas tentang pengontrolan sistem keamanan ruangan menggunakan Arduino UNO melalui media keypad membrane $4 \times 4$ dan voice via Bluetooth. Rancangan ini mempunyai komponen utama berupa Arduino dan komponen-komponen kecil lainnya beserta keypad membrane $4 \times 4$ dan voice via bluetooth sebagai I/Onya.

2. Penelitian yang dilakukan oleh Mangasi Sirait dan Kasmir Tanjung 2015 yang berjudul "Perancangan Sistem Keamanan Akses Buka Pintu Menggunakan RFID (Radio Frequensi Identification) dan Pengiriman Informasi ke Ponsel. Penelitian ini bertujuan sebagai pengamanan yang dapat digunakan dalam membuka pintu menggunakan RFID dan password sebagai kunci untuk mengakses buka pintu dari luar sedangkan untuk membuka dari dalam digunakan sensor PIR (Passive Infra Red). Selain itu pada sisem ini juga dapat memberikan informasi ke handphone pemilik dengan menggunakan modem. Informasi yang diberikan yaitu jika ada tindakan percobaan pencurian dengan memaksa membuka pintu dan mengakses pintu dengan menggunakan kunci (ID) yang tidak terdaftar dalam sistem. Semua sistem ini menggunakan mikrokontroler ATMEGA 8535 untuk megatur keseluruhan kegiatan sistem.

3. Penelitian yang dilakukan oleh Derian Indra Bramantio, Erwin Susanto, Ramadhan Nugraha 2016 yang berjudul "Perancangan dan Implementasi Keamanan Pintu Berbasis Pengenalan Wajah Dengan Metode Eigenface". Penelitian ini bertujuan untuk membuka dan mengunci pintu secara otomatis. Aplikasi yang dibuat terdiri dari Raspberry Pi sebagai mini PC dengan bahasa pemrograman python. Sistem ini diharapkan bisa mencari sendiri posisi wajah di dalam sebuah citra. Aplikasi yang digunakan adalah Eigenface atau yang biasa disebut dengan PCA ( Principle Component Analysis).

4. Penelitian yang dilakukan oleh Hadyan Setiawan, Agus Sofwan, dan Yuli Cristyono 2017 berjudul "Perancangan Aplikasi Smart Home Berbasis Android Untuk Pengendalian Keamanan Rumah Dengan Menggunakan Android Studio". Penelitian ini bertujuan untuk membuat perancangan aplikasi Smart Home Berbasis Android untuk keamanan pintu rumah sebagai penelitian. Sehingga pemilik rumah dapat memantau keadaan rumahnya dimana pun dan kapan pun.

5. Penelitian yang dilakukan oleh Endang Sunandar, Khanna Tiara, Mohamad Daud 2016 yang berjudul "System Lock and Controlling class Room dengan Interface Android Berbasis Arduino Uno". Penelitian ini bertujuan untuk menerapkan berbagai teori mengenai sistem pengontrolan secara elektrik, dan komunikasi data antara Mikrokontroller dengan Smarphone Android. Membuat sistem pintu ruangan kelas yang dikendalikan oleh mikrokontroller berbasis Arduino Uno dan dikontrol dengan aplikasi yang dibuat di Smartphone Android.

\section{METODE PENELITIAN}

Metode penelitian yang digunakan dalam pembuatan alat Smart Doorlock ini adalah metode SDLC (System Development Life Cycle) dengan model waterfall:

a. Tahap Analisa Kebutuhan

Pada tahap ini dilakukannya pengumpulan data dan penyusunan kebutuhan sistem.

b. Tahap Perancangan

Tahap ini, kebutuhan yang telah disusun sebelumnya diubah menjadi bentuk flowchart dimana akan dijelaskan mulai dari masukan hingga hasil.

c. Tahap Implementasi

Setelah dirancang, maka pada tahap ini rancangan tersebut akan diimplementasikan.

d. Tahap Testing 
Setelah sistem diimplementasikan selanjutnya sistem akan diuji coba secara keseluruhan.

e. Tahap Pemeliharaan

Tahap ini merupakan tahapan terakhir dari metode ini. Pada tahap pemeliharaan ini sistem yang telah dibuat dapat dijalankan sesuai dengan fungsinya dan tidak terdapat error.

\section{LANDASAN TEORI}

\section{Definisi Smart Door Lock}

Smart door lock adalah sebuah kunci pintu yang untuk pengoperasianya dapat dilakukan dengan cara yang tidak biasa [1]. Dalam hal ini pengoperasian dapat dilakukan dengan menggunakan sidik jari, password, ketukan, komunikasi bluetooth bahkan dengan menggunakan jaringan internet. Fungsi utama dari smart door lock adalah untuk membatasi orang yang dapat mengakses pintu sehingga hanya orang-orang tertentu yang mendapat ijin dan mendapat wewenang yang dapat mengakses pintu tersebut. Dengan smart door lock ini maka keamanan rumah dapat lebih terjamin.

\section{Definisi Voice Recognition}

Voice Recognition yaitu Proses pengenalan secara otomatis suatu sinyal suara dengan membandingkan pola karakteristiknya dengan sinyal suara yang menjadi referensi atau acuan [2]. Fungsi dari voice recognition adalah dapat mengidentifikasi seseorang melalui suaranya. Voice recognition dibagi menjadi 2 bagian antara lain speech recognition dan speeker recognition. Jika voice recognition dapat mengidentifikasi seseorang melalui suaranya maka speech recognition dapat mengidentifikasi apa yang diucapkan oleh seseorang. Sedangkan speeker recognition adalah sistem pengenalan identitas yang diklaim oleh seseorang dari suaranya atau berdasarkan orang yang berbicara.

\section{Definisi Raspberry Pi 3}

Raspberry Pi 3 adalah generasi ketiga dari Raspberry Pi, menggantikan Raspberry Pi 2 Model B pada Februari 2016 [3]. Raspberry Pi 3 memiliki bentuk yang identik dengan Raspberry Pi 2 sebelumnya (dan Pi 1 Model B +) dan memiliki kompatibilitas lengkap dengan Raspberry Pi 1 dan 2. Pada perangkat terbarunya ini Raspberry menambahkan fitur built-in wireless dan processor yang lebih bertenaga yang belum pernah dimiliki pada versi sebelumnya.

\section{Definisi Solenoid Door Lock}

Solenoid Door Lock adalah salah satu solenoid yang difungsikan khusus sebagai solenoid untuk pengunci pintu secara elektronik [4]. Solenoid ini mempunyai dua sistem kerja, yaitu Normaly Close (NC) dan Normaly Open (NO). Perbedaanya adalah jika cara kerja solenoid NC apabila diberi tegangan, maka solenoid akan memanjang (tertutup). Dan untuk cara kerja dari Solenoid NO adalah kebalikannya dari Solenoid NC. Biasanya kebanyakan solenoid Door Lock membutuhkan input atau tegangan kerja 12V DC, tetapi ada juga solenoid Door Lock yang hanya membutuhkan input tegangan 5V DC sehingga dapat langsung bekerja dengan tegangan output dari pin IC digital. Namun jika menggunakan Solenoid Door Lock yang $12 \mathrm{~V}$ DC. Pada kondisi normal solenoid dalam posisi tuas memanjang / terkunci. Jika diberi tegangan tuas akan memendek/terbuka. Solenoid ini bisa digabungkan dengan sistem pengunci elektrik berbasis RFID dan password. Cocok dipakai untuk pengunci pintu ataupun locker/lemari. Membutuhkan power supply $12 \mathrm{~V}$ dan sebuah relay untuk mengaktifkannya.

\section{Definisi Uln2803}

ULN2803 adalah chip Integrated Circuit (IC) berupa rangkaian transistor darlinton dengan tegangan tinggi [5]. Hal ini memungkinkan untuk membuat antarmuka sinyal TTL dengan beban tegangan tinggi. Chip mengambil sinyal tingkat rendah (TTL,CMOS, PMOS, NMOS - 
yang beroperasi pada tegangan rendah dan arus rendah) yang bertindak sebagai relay, menyalakan atau mematikan tingkat sinyal yang lebih tinggi disisi yang berlawanan.

\section{Definisi Motor Servo}

Motor servo adalah sebuah motor DC yang dilengkapi rangkaian kendali dengan sistem closed feedback yang terintegrasi dalam motor tersebut [6]. Pada motor servo posisi putaran sumbu (axis) dari motor akan diinformasikan kembali kerangkaian kontrol yang ada didalam motor servo.

\section{HASIL DAN PEMBAHASAN}

Berdasarkan permasalahan yang ada pada ruangan server dalam sistem membuka atau mengunci pintu ruangan adalah masih menggunakan kunci konvensional sebagai alat untuk membuka atau mengunci pintu ruangan server. Sehingga saat staff teknik ingin membuka pintu kunci harus mencari kunci konvensional terlebih dahulu kemudian memasukkan kunci kedalam lubang lalu mendorong pintu secara manual.

Untuk memecahkan masalah diatas, dirancanglah sistem Smart Door Lock untuk membuka ataau mengunci pintu ruangan server dengan menggunakan perintah suara. Dengan membuka aplikasi DoorLock pada smartphone yang telah terhubung dengan bluetooth dan internet lalu memberikan perintah suara. Setelah itu perintah suara yang diterima akan di proses oleh Raspberry pi 3 kemudian memberikan data pada ULN 2803 sebagai ic untuk meningkatkan tegangan sehingga dapat menggerakan solenoid sebagai door lock sesuai perintah suara yang telah diberikan. Setelah itu raspberry memberikan perintah kepada motor servo untuk membuka atau menutup pintu sesuai dengan perintah suara yang diberikan oleh staff teknik.

Berikut ini diagram blok rangkaian secara keseluruhan ditunjukkan gambar 1

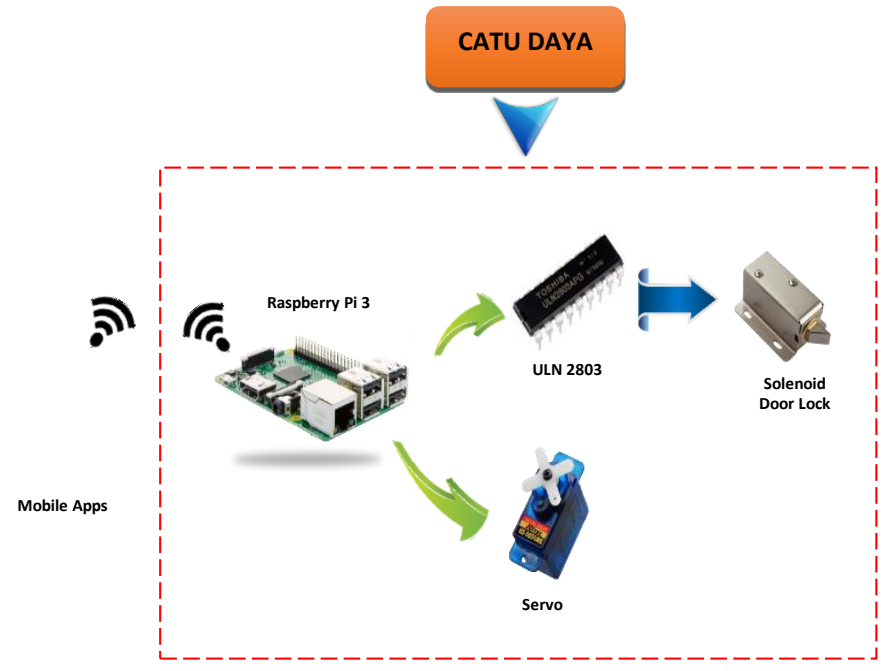

Gambar 1. Diagram Blok Rangkaian

Keterangan dan penjelasan diagram blok di atas adalah:

1. Catu daya adalah sebagai sumber memberikan tegangan.

2. Mobile Apps sebagai perangkat yang mengirimkan perintah dan suara ke Raspberry melalui media bluetoth.

3. Raspberry sebagai perangkat yang menerima suara dan diolah berdasarkan perintah yang diberikan. 
4. ULN 2803 berfungsi untuk melakukan open/close Solenoid doorlock setelah menerima perintah yang diberikan

5. Servo berfungsi untuk melakukan open/close pintu setelah menerima perintah dari raspberry

\section{FLOWCHART}

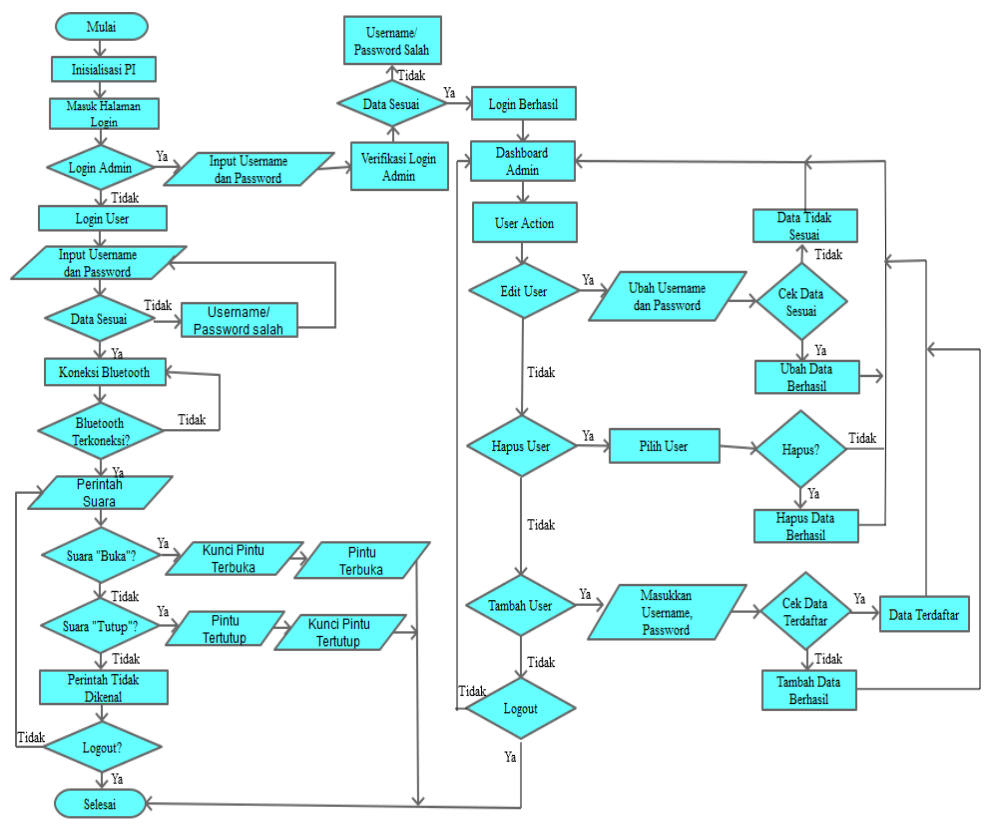

Gambar 2. Flowchart sistem

Berdasarkan gambar 2. Flowchart sistem diatas terdapat:

1. 2 (dua) simbol terminal, yang berperan sebagai "Mulai" dan "Selesai" pada aliran proses flowchart sistem penyampaian informasi yang berjalan.

2. 15 (lima belas) simbol proses, yang menyatakan sebuah proses inisialisasi Pi, masuk halaman login, login user, koneksi Bluetooth, username atau password salah, perintah tidak dikenal,verifikasi login admin, login berhasil, dashboard, user action, pilih user, data tidak sesuai, ubah data berhasil, hapus data berhasil, dan tambah data berhasil.

3. 8 (delapan) simbol Data yang menyatakan user login akun dengan memasukkan id dan password, jika id dan password benar maka user memasukkan perintah suara "buka" maka kunci dan pintu terbuka, perintah suara "tutup" maka pintu tertutup dan kunci tertutup. Adapun simbol data yang menyatakan ubah username, password dan memasukkan username, password.

4. 14 (empat belas) simbol decision, yang berperan untuk menunjukkan sebuah langkah pengambilan keputusan jika 'ya" atau "tidak' yaitu login admin?, data sesuai?, edit user?, hapus user?, tambah user?, cek data sesuai?, bluetooth terkoneksi?, suara "buka"?, suara "tutup"?,dan logout?

\section{HAK AKSES}

Dalam penggunaan alat Smart DoorLock ini hanya dapat digunakan oleh staff yang memiliki id dan password yang telah terdaftar. Jika staff tidak mempunyai id dan password maka tidak dapat membuka kunci pintu menggunakan aplikasi DoorLock. 


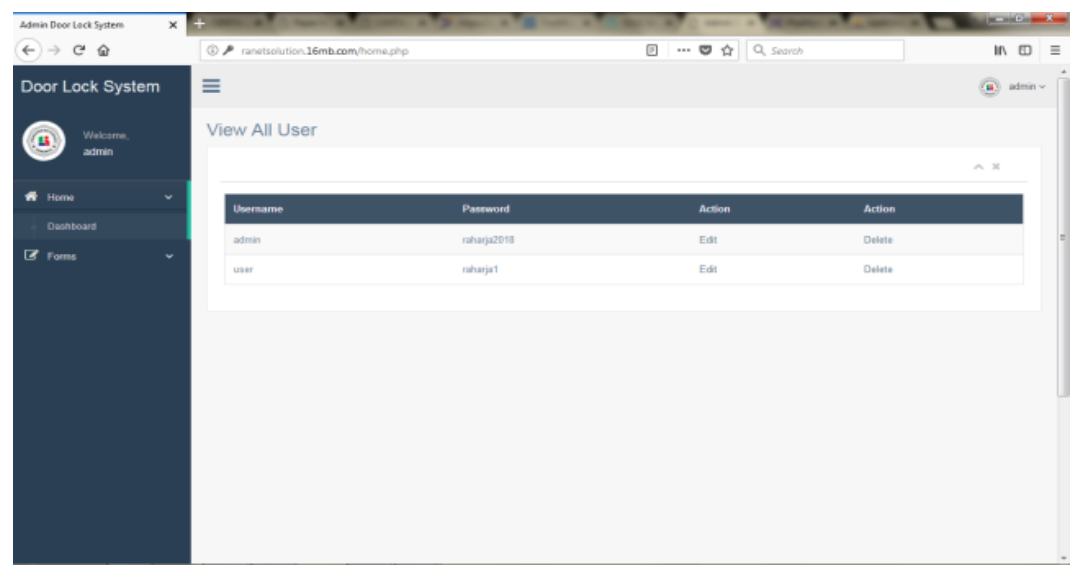

Gambar 3. Menu Dashboard Admin

\section{IMPLEMENTASI}

Pada tahap ini merupakan tahan-tahap untuk merealisasikan dari sistem yang dirancang. Yang dimulai dari tahap pengumpulan data -data dan diharapkan dapat membantu dan mendukung hingga sampai tercapainya dalam penerapanya.

\section{Pengujian Black Box Login Pada Smartphone}

Untuk dapat membuka atau mengunci pintu petugas harus login terlebih dahulu pada aplikasi DoorLock yang ada pada Smartphone.

Tabel 1. Pengujian Login pada Smartphone

\begin{tabular}{|c|c|c|c|c|c|}
\hline No & Skenario Pengujian & $\begin{array}{c}\text { Test } \\
\text { Case }\end{array}$ & $\begin{array}{c}\text { Hasil Yang Di } \\
\text { harapkan }\end{array}$ & $\begin{array}{c}\text { Hasil } \\
\text { Pengujian }\end{array}$ & $\begin{array}{c}\text { Kesimpula } \\
\mathrm{n}\end{array}$ \\
\hline 1. & $\begin{array}{c}\text { Menampilkan halaman } \\
\text { Login pada Smarphone }\end{array}$ & $\begin{array}{c}\text { Menampilkan } \\
\text { tampilan halaman } \\
\text { activity }\end{array}$ & \begin{tabular}{c}
\hline \\
$\vdots$
\end{tabular} & Valid \\
\hline
\end{tabular}

\section{Pengujian Black Box Solenoid}

Solenoid sebagai doorlock akan membuka kunci pintu setelah user memberikan perintah "buka" dan solenoid akan mengunci pintu setelah user memberikan perintah "tutup".

\section{Tabel 2. Pengujian Black Box Solenoid}

\begin{tabular}{|c|c|c|c|c|c|}
\hline No & Skenario Pengujian & Test Case & $\begin{array}{c}\text { Hasil Yang } \\
\text { Diharapkan }\end{array}$ & $\begin{array}{c}\text { Hasil } \\
\text { Pengujian }\end{array}$ & $\begin{array}{c}\text { Kesim } \\
\text { pulan }\end{array}$ \\
\hline 1. & $\begin{array}{c}\text { User memberikan } \\
\text { perintah suara } \\
\text { "Buka" }\end{array}$ & Valid \\
\hline 2. & $\begin{array}{c}\text { User memberikan } \\
\text { perintah suara } \\
\text { "Tutup" }\end{array}$ & $\overline{\text { Solenoid membuka }}$ & & & Vunci pintu \\
\hline
\end{tabular}




\section{Pengujian Black Box Motor Servo}

Motor servo sebagai motor penggerak pintu. Motor servo akan membuka atau menutup pintu setelah mendapatkan perintah dari user yang di proses oleh Raspberry.

Tabel 3. Pengujian Black Box Motor Servo

\begin{tabular}{|c|c|l|c|c|c|}
\hline No & Skenario Pengujian & Test Case & $\begin{array}{c}\text { Hasil Yang } \\
\text { Diharapkan }\end{array}$ & $\begin{array}{c}\text { Hasil } \\
\text { Penguji } \\
\text { an }\end{array}$ & $\begin{array}{c}\text { Kesimpula } \\
\mathrm{n}\end{array}$ \\
\hline 1. & $\begin{array}{c}\text { User memberikan } \\
\text { perintah suara "Buka" }\end{array}$ & $\begin{array}{c}\text { Motor Servo } \\
\text { membuka pintu }\end{array}$ & Valid \\
\hline 2. & $\begin{array}{c}\text { User memberikan } \\
\text { perintah suara "Tutup" }\end{array}$ & $\begin{array}{c}\text { Motor servo } \\
\text { menutup pintu }\end{array}$ & Valid \\
\hline
\end{tabular}

\section{Cara Kerja Prototype}

Sistem pengontrolan ini dirancang untuk memudahkan user dalam membuka atau mengunci pintu yaitu sudah tidak menggunakan kunci manual melainkan dengan voice (suara).

\section{Masukan(Input)}

Dalam sistem pengontrolan ini yang menjadi masukan atau input yaitu suara user melalui smartphone yang dikirimkan ke Raspberry.

Cara kerjanya:

User membuka aplikasi doorlock kemudian mengkoneksikan bluetooth smartphone dengan bluetooth raspberry setelah terkoneksi user akan mengucapkan kata "buka" atau "tutup"

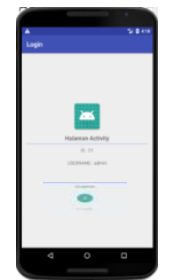

Gambar 4. Aplikasi terkoneksi

\section{Proses(Process)}

Komponen pada proses terdapat Raspberry

Cara kerjanya:

Raspberry menerima suara dan diolah berdasarkan perintah yg diberikan. Kemudian Raspberry mengeluarkan output atas input yang diterima. 


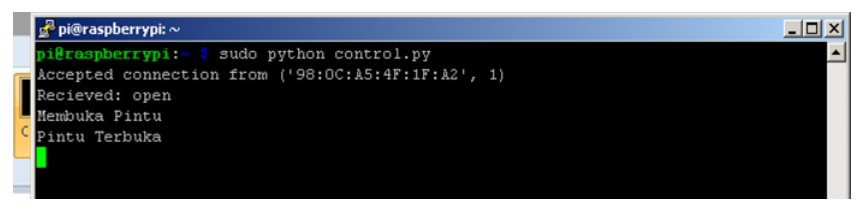

Gambar 5. Raspberry menerima input

\section{Keluaran(Output)}

Output dikeluarkan ke ULN 2803 untuk melakukan open/close kunci pintu. Kemudian Raspberry memberikan perintah ke servo untuk open/close pintu.

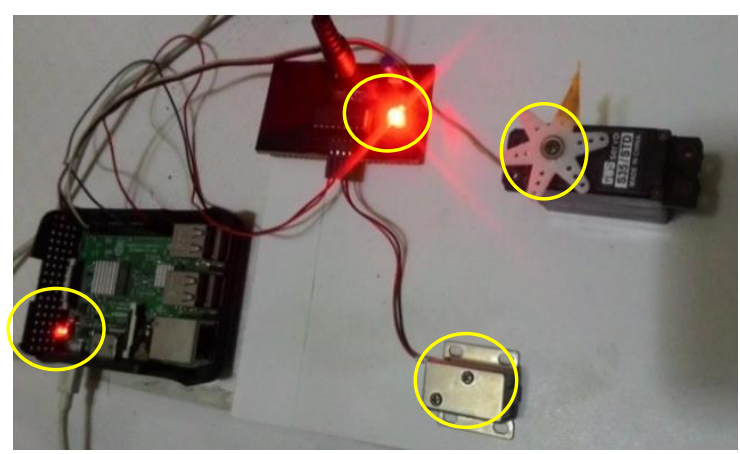

Gambar 6. Rangkaian proses buka pintu

\section{KESIMPULAN}

Berdasarkan keseluruhan dari hasil pengamatan, percobaan dan pembahasan dapat di ambil kesimpulan sebagai berikut:

1. Perancangan raspberry pi 3 agar dapat memberikan perintah untuk membuka kunci pintu adalah ketika raspberry pi 3 menerima perintah berupa kata "buka" yang diucapkan oleh user maka raspberry akan memberikan nilai 1 terhadap pin GPIO 21, pin ini dihubungkan ke IC ULN 2803 yang memiliki fungsi sebagai penguat tegangan. Ketika pin GPIO 21 bernilai 1, maka pin 18 pada ULN 2803 akan memberikan nilai 1 pada solenoid sehingga solenoid terbuka. Kemudian pada jeda waktu yang telah ditentukan raspberry akan memberikan nilai 1 ke pin GPIO 27 sehingga motor servo akan bergerak untuk membuka pintu.

2. Perancangan sistem pembuka kunci pintu menggunakan voice recognition adalah dengan menggunakan aplikasi "Doorlock" yang terinstall pada smartphone. Kemudian user memasukkan id dan password sesuai dengan data yang telah terdaftar. Setelah itu bluetooth pada smartphone dan raspberry aktif maka aplikasi "Doorlock" tadi akan otomatis terkoneksi dengan sistem dan dapat menerima perintah berupa voice yang diberikan oleh user. Kemudian raspberry menerima masukan lalu diproses berdasarkan perintah yang diberikan. Setelah diproses kemudian raspberry memberikan hasil output kepada ULN 2803 untuk menggerakan doorlock

3. Penggunaan voice recognition pada kunci pintu ruang tehnik lebih mudah digunakan karena pada sistem berjalan kunci pintu pada ruang tehnik masih menggunakan kunci fisik. Sedangkan, kunci fisik mudah hilang atau tertinggal sehingga staff tehnik tidak dapat masuk kedalam ruangan. Dengan menggunakan voice recognition ini sebagai kunci pintu, staff tehnik bisa dengan mudah masuk kedalam ruangan dengan mengucapkan kata "buka" dengan terlebih dahulu login melalui smartphone. 


\section{DAFTAR PUSTAKA}

[1] Iman, Fadlan Fakhrul. 2018. Purwarupa Smart Door Lock Menggunakan Multi Sensor Berbasis Sistem Arduino. (Laporan Thesis, Universitas Teknologi Yogyakarta, Kota Yogyakarta).

[2] Setiawan, Septian Andi dan Yuri Ariyanto. 2015. "Voice Recognition: Pengenalan Chord ukulele 4 senar dengan menggunakan metode back Propagation Neural Network". Politeknik Negeri Malang. Prosiding Seminar Informatika Aplikatif Polinema 2015. ISSN: 2460-1160

[3] Anggraini, Astri. 2016. "Rancang Bangun Open/Close Pintu Ruangan Otomatis Menggunakan Voice Recognition Berbasis Raspberry Pi”. (Laporan Tugas Akhir, Politeknik Negeri Sriwijaya Palembang, Palembang).

[4] C Saghoa Yohanes, Sherwin R.U.A. Sompie, Novi M. Tulung. 2018. Kotak Penyimpanan Uang Berbasis Mikrokontroler Arduino Uno. Universitas Sam Ratulangi Manado. Jurnal Teknik Elektro dan Komputer Vol. 7 No.2 (2018), ISSN : 2301-8402

[5] Hidayati, Elok Dwi Swastani. 2015. "Pendeteksi dan Penetralisir Polusi Asap Dengan Kontrol Melalui Aplikasi Android (Rancang Bangun Perangkat Lunak)". (Laporan Tugas Akhir. Politeknik Negeri Sriwijaya. Palembang).

[6] Akbar Fadillah, Muhammad. 2016. Sistem Keamanan Ruangan Menggunakan Voice Via Bluetooth Berbasis Arduino Pada Kementerian Agama Kabupaten Tangerang. (Laporan Skripsi, STMIK Raharja. Tangerang).

[7] Sirait,Mangasi. Kasmir Tanjung. 2015. "Perancangan Sistem Keamanan Akses Buka Pintu Menggunakan RFID (RADIO FREQUENCY IDENTIFICATION) Dan Pengiriman Informasi Ke Ponsel". Jurnal SINGUDA ENSIKOM Fakultas Teknik Universitas Sumatera Utara VOL.13 NO.37/DESEMBER 2015. ISSN 2337-3237

[8] Derian Indra Bramantio, Erwin Susanto, Ramdhan Nugraha. 2016. "Perancangan Dan Implementasi Keamanan Pintu Berbasis Pengenalan Wajah Dengan Metode Eigenface”. Jurnal Penelitian dan Pegembangan Telekomunikasi, Kendali, Komputer, Elektrik, dan Elektronika (TEKTRIKA) Juli 2016 - Volume 1, Nomor 2.

[9] Setiawan. Hadyan, Agus Sofwan, dan Yuli Christyono. 2017. "Perancangan Aplikasi Smart Home Berbasis Android Untuk Pengendalian Keamanan Rumah Dengan Menggunakan Android Studio". Jurnal TRANSIENT Universitas Diponegoro, VOL. 6, NO. 3, SEPTEMBER 2017, ISSN: 2302-9927, 504-513

[10] Sunandar, E., Tiara, K., \& Daud, M. (2018). SYSTEM LOCK AND CONTROLLING CLASS ROOM DENGAN INTERFACE ANDROID BERBASIS ARDUINO UNO. CCIT Journal,9(2), 157-167. Retrieved from http://ejournal.raharja.ac.id/index.php/ccit/article/view/181 